"Because everything is relatively undisturbed, it likely wasn't a massive flood," he says.

But the streak connects all of the eggs, suggesting that the dinosaurs laid them in a single breeding season. "Geologically, I don't think we could've asked for a better site," says Zelenitsky.

"It's a compelling story," says Balanoff, adding that the researchers back it up with a strong analysis.
The team was also able to identify the type of dinosaur that was probably responsible. The eggs' exterior and interior textures, as well as shell thickness, point to a kind of non-avian theropod, a large group that includes dinosaurs such as velociraptors and Tyrannosaurus.

The researchers also estimated that just over half of the nests had at least one successful hatch owing to the number of fragmented eggs. This relatively high rate mirrors the hatching success of modern birds and crocodiles that guard their nests, as opposed to those that abandon or only occasionally check them.

Daniel Barta, a palaeontologist at California State University, Los Angeles, agrees that such a high rate suggests that some dinosaurs tended their nests. But he cautions that eggs that have hatched and those that predators have cracked open can often look similar.

\title{
China feels the heat over rogue CFC emissions
}

\section{The government says it will build a monitoring network to understand what is going on.}

\section{BY DAVID CYRANOSKI}

$\mathrm{W}$ hen atmospheric models traced a mysterious spike of an ozonedestroying gas to two provinces in China earlier this year, scientists waited to see how the Chinese government, and other nations, would respond to this possible violation of international law.

Now the government is under pressure to act - and has presented a plan to help it track and reduce emissions of the chemical, known as trichlorofluoromethane or CFC11. Measures include establishing a national monitoring network to track ozone-depleting chemicals, along with heftier penalties for companies caught illegally producing the chemical.

Details of the plan emerged in notes released last month from a May meeting of the Multi-

lateral Fund for the Implementation of the Montreal Protocol in Montreal, Canada.

The document "sets the stage for real progress on this important issue", says David Fahey, director of the Chemical Sciences Division at the US National Oceanic and Atmospheric Administration (NOAA) Earth System Research Laboratory in Boulder, Colorado.

The Chinese environment ministry disputes that there is enough evidence to pin the recently discovered spike in emissions on China, but agrees that more data are needed to understand the problem.

CFC-11 was once a popular refrigerant, and widely used to produce polyurethane foam insulation. But the legally-binding 1987 Montreal Protocol called for its production and trade to be phased out by 2010 .

The treaty worked, and global CFC-11 production dropped until 2013, when a surprising slowdown in that decline suggested that there was a new source of emissions.

In a study published in Nature in May 2018, researchers traced the spike to east Asia (S. A. Montzka et al. Nature 557, 413-417; 2018). In another published in May 2019, they traced it more precisely, to the provinces of Hebei and Shandong in northeastern China, using data from monitoring stations in Japan and South Korea (M. Rigby et al. Nature 569, $546-550 ; 2019)$. Scientists suspect that factories in those provinces might have resumed production of a CFC-11-based foam insulator. Because China has ratified the Montreal Protocol, it is obliged to address any illegal CFC-11 production.

In May, China's environment ministry questioned the conclusions of the most

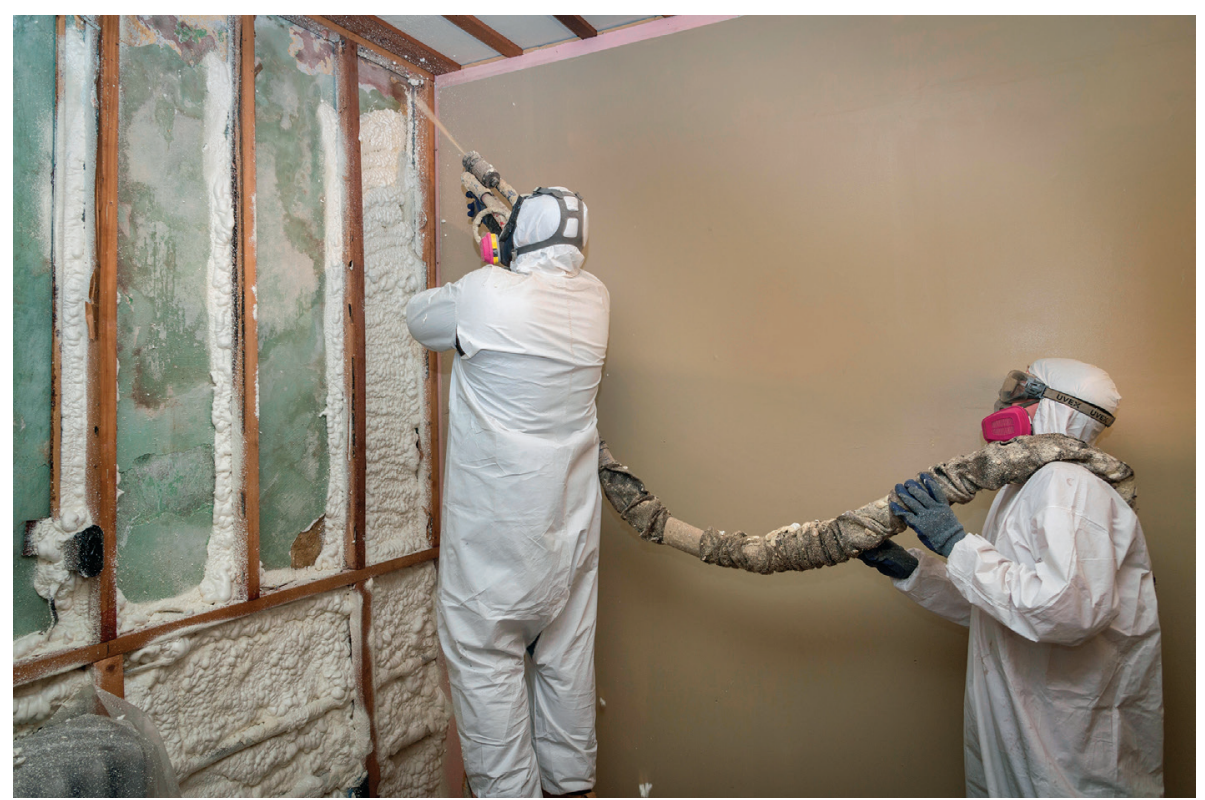

A source of ozone-destroying gas has been tracked to China, and foam manufacturers are in the firing line. recent study, noting "great uncertainty" in the reported amount and location of emissions. But the statement also said that the study "makes us realize the importance of atmosphere monitoring".

China has released few details about its plan for a national monitoring network. But the documents from the Montreal meeting say routine monitoring will begin within three years in several key cities. If the network uses stations close to Hebei and Shandong, it could pinpoint the source of the mysterious CFC-11 spike, says scientists. That in turn would aid efforts to eliminate the spike, says Stephen Montzka, an atmospheric chemist at the NOAA Earth System Research Laboratory who was part of the team that identified 
- the spike. Montzka hopes that any data gathered by the national network will be open to the global scientific community.

The Chinese government acknowledges some illegal CFC-11 production: before the Montreal meeting, it reported to the multilateral fund that it had seized 114 tonnes of illegally produced CFC-11 since 2012 .

But such amounts could not account for the roughly 7,000 tonnes of CFC-11 that, according to estimates in the 2019 Nature paper, is being newly produced each year. (Nature's news team is editorially independent of its journal team.)

Independent scientists say they have confidence in those estimates. "The measurements are of a very high quality," says Claire Reeves, an atmospheric chemist at the University of East Anglia in Norwich, UK. She is leading a team that is building a CFC-11 data set from samples taken in northern Taiwan, which also points to a source of CFC-11 emissions in northeastern China, she says.

A former central-government employee who worked on the regulation of ozonedepleting chemicals, and who asked to remain anonymous because of the sensitivity of the issue, says it is likely there is production of these chemicals that the Chinese government does not know about. Only a few people at local environment and ecology bureaus are assigned to oversee an entire province's monitoring and enforcement efforts on these gases, the source says: "It's not a core task of the ministry."

Attempts by Nature's news team to contact the environment and ecology board for Hebei province were unsuccessful. Shandong province responded to queries about its efforts by forwarding "We can work statements from the for the continued national environsuccess and ment ministry. The progress of national ministry did the Montreal not respond directly Protocol." to the source's comments, but its spokesperson acknowledged that some problems have arisen since the Montreal Protocol was established. "We believe that as part of international collaborative efforts, we can work for the continued success and progress of the Montreal Protocol."

\section{ONE THOUSAND STATIONS}

To measure CFC-11, the new network could make use of China's more than 1,000 existing air-quality monitoring stations.

Some are already used to measure CFC11 , but finding the source of the spike that emerged in 2013 would require more frequent sampling over a longer period than is seen for the data from these stations that have appeared in the literature, says Montzka.

China also told the multilateral-fund meeting that it will establish six new laboratories capable of testing for ozone-depleting chemicals in insulation foam, which will speed up the testing of suspect products and help the government to crack down on such activity. Two will be in Beijing and one in Jinan, the capital of Shandong, according to the environment ministry.

Many representatives at the meeting in Montreal, including those from the United States and Japan, the top two contributors to the fund, expressed frustration with China's apparent failure to curb emissions and demanded quick action. Japan even warned that it might withdraw funding if the cause of the CFC-11 emissions is not addressed.

China says that it will report on its progress at the next meeting of the fund in December.

\section{CLARIFICATION}

The News Feature 'Ancient proteins tell their tales' (Nature 570, 433-436; 2019) did not make clear that the Stephanorhinus work cited in reference 6 was led by Enrico Cappellini.

\section{nature MASTERCLASSES}

\section{Online Course in Scientific Writing and Publishing}

Delivered by Nature Research journal editors, researchers gain an unparalleled insight into how to publish.

\section{Try a free sample of the course at masterclasses.nature.com}

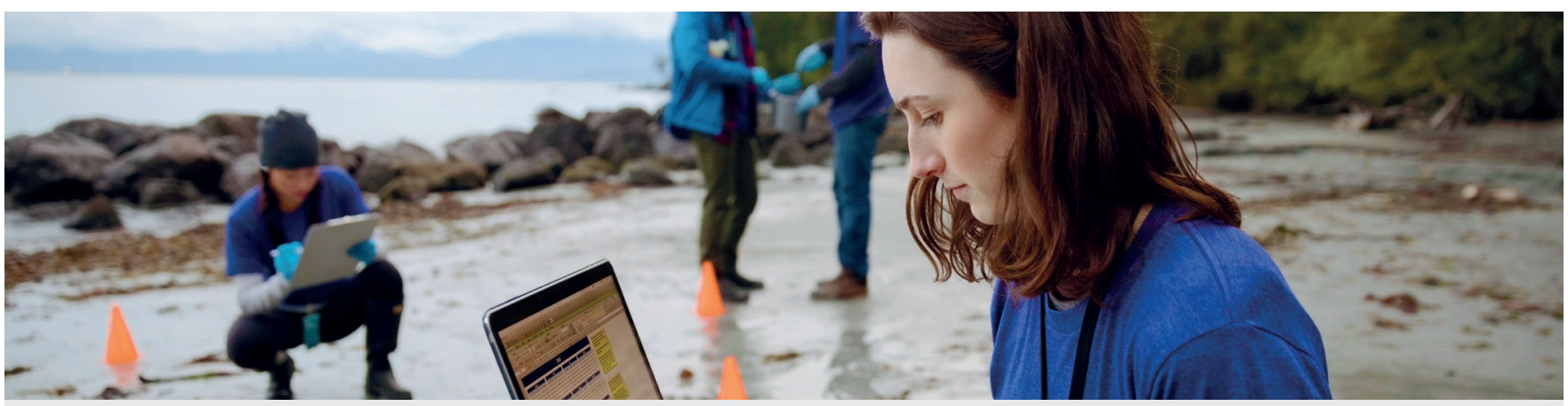

Bite-size design for busy researchers • Subscribe as a lab or institution 